\title{
The effect of physical activity and its interaction with nutrition on bone health
}

\author{
Niamh M. Murphy and Paula Carroll \\ Centre for Health Behaviour Research, Waterford Institute of Technology, Waterford, Republic of Ireland
}

\begin{abstract}
Physical activity (PA) is a popular therapy for the prevention and treatment of bone loss and osteoporosis because it has no adverse side effects, it is low cost, and it confers additional benefits such as postural stability and fall prevention. Bone mass is regulated by mechanical loading, and is limited but not controlled by diet. The mechanism by which strain thresholds turn bone remodelling 'on' and 'off' is known as the mechanostat theory. Research in animals has shown that optimal strains are dynamic, with a high change rate, an unusual distribution and a high magnitude of strain, but the results of randomized controlled trials in human subjects have been somewhat equivocal. In the absence of weight-bearing activity nutritional or endocrine interventions cannot maintain bone mass. Biochemical markers of bone turnover predict bone mass changes, and findings from our research group and others have shown that both acute and chronic exercise can reduce bone resorption. Similarly, $\mathrm{Ca}$ intervention studies have shown that supplementation can reduce bone resorption. Several recent meta-analytical reviews concur that changes in bone mass with exercise are typically 2-3\%. Some of these studies suggest that $\mathrm{Ca}$ intake may influence the impact of PA on bone, with greater effects in Ca-replete subjects. Comparative studies between Asian (high PA, low Ca intake) and US populations (low PA, high $\mathrm{Ca}$ intake) suggest that PA may permit an adaptation to low $\mathrm{Ca}$ intakes. Whether $\mathrm{Ca}$ and PA interact synergistically is one of the most important questions unanswered in the area of lifestyle-related bone health research.
\end{abstract}

\section{Physical activity: Calcium: Bone mass: Bone turnover}

Physical activity (PA) is a popular therapy for the prevention and treatment of bone loss and osteoporosis because it has no adverse side effects, it is low cost and it confers additional benefits such as postural stability and fall prevention. Strain thresholds turn bone remodelling 'on' and 'off' at a local level by a mechanism known as the mechanostat (or minimum effective strain; MES) theory. Research in animals has shown that optimal strains are dynamic, with a high change rate, an unusual distribution and a high magnitude of strain. Bone is also sensitive to metabolic stimuli that govern bone turnover at a systemic level. Several recent meta-analytical reviews concur that changes in bone mass with PA are typically $2-3 \%$. Ca intervention studies have generally shown that supplementation can help maintain bone mass in adults, or improve bone mass in children (1-3\%). However, in the absence of weight-bearing activity, nutritional or endocrine interventions cannot maintain bone mass. Biochemical markers of bone turnover are also useful for quantifying the effect of
PA and nutrition interventions on bone. However, to date, most researchers have not adequately accounted for the inherent variability of these markers. Whether $\mathrm{Ca}$ and PA interact synergistically is one of the most important questions unanswered in the area of lifestyle-related bone health research. Recent longitudinal studies in children suggest that $\mathrm{Ca}$ intake may influence the impact of PA on bone, with greater effects in Ca-replete subjects (Iuliano-Burns et al. 2003; Specker \& Binkley, 2003).

The notion that PA has a positive effect on bone dates back approximately 400 years to the time of Galileo. More recently, there has been an unprecedented level of interest in the area. Nutrition is another key lifestyle factor that influences bone, and its effects are extensively reviewed elsewhere in this symposium. The present review paper focuses on $\mathrm{Ca}$ as the most important nutrient interacting with PA in impacting on bone. The relative contributions of $\mathrm{Ca}$ and PA to bone health, and the interactions between PA and $\mathrm{Ca}$ will be discussed. It has been suggested that $\mathrm{Ca}$

\footnotetext{
Abbreviations: BMD, bone mineral density; CD, critical difference; CTx, cross-linked C-telopeptides; $\mathrm{CV}_{\mathrm{I}}$, within-subject biological variance; DEXA, dualenergy x-ray absorptiometry; ES, effect sizes; MES, mechanostat or minimum effective strain; PA, physical activity; PTH, parathyroid hormone; GH, growth hormone.

*Corresponding author: Dr Niamh Murphy, fax +35351378292, email nmurphy@wit.ie
} 
intake modifies the bone response to increased PA (Kelly et al. 1990), but it is only very recently that this hypothesis has been tested. The present paper will also review the use of biochemical markers for elucidating the mechanisms of the bone response to PA or nutritional interventions.

\section{The effects of physical activity on skeletal tissue: mechanisms}

Skeletal tissue is responsive to both mechanical and metabolic stimuli, which govern bone turnover at a local and systemic level respectively. It has been hypothesized that any functional level of bone mass is the result of a balance between the mechanical drive towards formation (governs the coupling of bone turnover) and the metabolic drive towards resorption (governs the rate of bone turnover via circulating hormones; Rubin \& Lanyon, 1984; Inman et al. 1999). PA has the unique ability to activate the bone multicellular unit via both a mechanical and a metabolic stimulus, either independently or simultaneously, thereby promoting the retention of bone mass.

Mechanically-induced strain is the key intermediary variable between loading and resulting bone formation. At the end of the 19th century Julius Wolff (1892) postulated that bone adapts to mechanical loads to produce structures best fitted to withstand those forces (Wolff's Law). Since then, the optimal force (magnitude and type) required to elicit an osteogenic response and its mode of application have generated considerable research interest. Frost (1987) identified a strain threshold that must be exceeded for skeletal adaptation to occur, thereby initiating the MES theory. Mechanical forces $>1500-2000 \mu \epsilon$ (about $6 \%$ of the normal fracture strain threshold of $25000 \mu \epsilon)$ stimulate uncoupling of bone remodelling in favour of bone formation, thereby strengthening bone and increasing bone mass (Frost, 1991). Strains below this remodelling threshold are said to be in the physiological loading zone, within which the activity within the bone multicellular unit remains balanced. In the absence of sufficient mechanical strain (i.e. $<200 \mu \epsilon,<0.8 \%$ of the fracture strain threshold), as experienced during periods of immobilization and/or bed rest, bone remodelling uncouples in favour of resorption and bone loss results. An activity such as running generates ground reaction forces of $1 \cdot 5-2 \cdot 0$ times body weight and is generally equivalent to approximately $800 \mu \epsilon$. Jumping generates forces of three or four times body weight in preand post-menopausal women (Bassey et al. 1998), and thus produces forces above the MES.

In addition to the absolute magnitude of the strain, animal models have demonstrated that the most effective types of strains were dynamic (i.e. cyclic change in internal strain) (O'Connor \& Lanyon, 1982; Lanyon, 1984), high in rate (Lanyon et al. 1982; Lanyon, 1996) and of abnormal distribution (Lanyon et al. 1982; Carter, 1987; Lanyon, 1996). It was also found that strain-induced distortion (change in length divided by original length) was more osteogenic than stress (force) alone (Burr \& Martin, 1992). However, the number of loading cycles appears to be less important than the magnitude or rate of strain, as skeletal tissue becomes desensitized to mechanical loading above thirty-six consecutive loading cycles $(72 \mathrm{~s} / \mathrm{d}$; Rubin \&
Lanyon, 1984). According to Turner \& Robling (2003) $>95 \%$ of the desensitizing effect of repetitive loading occurs after twenty loading cycles, although $98 \%$ of the mechano-sensitivity lost is restored after $24 \mathrm{~h}$ of rest (Robling et al. 2001). This finding suggests that the osteogenic response to exercise can be enhanced by including rest periods between short vigorous bouts of mechanical loading.

The exact intermediary steps between matrix strain and bone cell response have yet to be clearly defined, but a number of mechanisms have been proposed: release of prostaglandins (prostaglandin $\mathrm{E}_{2}$ ); flow-related shear stresses on cell membranes; repair in response to microdamage of skeletal tissue.

In addition to imparting mechanical stress on bone, PA may also generate an endocrine effect. The primary endocrine response to metabolic stress is the stimulation of growth hormone $(\mathrm{GH})$ release from the pituitary. Acute physical exercise is a well-known stimulus for $\mathrm{GH}$ secretion, and it is suggested that the $\mathrm{GH}$ response to exercise is influenced by the intensity, duration, work output and the amount of muscle mass involved. Generally, GH is produced in proportion to the relative stress of the workload for that individual, as long as sufficient metabolic stress is achieved. Considerable research has been undertaken in order to define the criteria necessary to bring about such metabolic conditions. Briefly, the lowest intensity of exercise needed to elicit a $\mathrm{GH}$ response is $60 \mathrm{~min}$ at $10-15 \%$ of the maximum $0_{2}$ consumption, while 20 min at $70-80 \%$ of the maximum $0_{2}$ consumption would also suffice (Cuneo \& Wallace, 1994). Fesling et al. (1992) reported, however, that once the exercise was above the individual's anaerobic threshold, a GH surge could be seen after only $10 \mathrm{~min}$. It would appear, however, that two equivalent total workloads performed in two distinct exercise protocols would induce two different $\mathrm{GH}$ responses. Prolonged continuous protocols as opposed to shorter ones with twice the work rate reflect lower metabolic stress and lactate levels and consequently poorer $\mathrm{GH}$ responses. Data reported by Hatori et al. (1993) showed a significant increase $(P<0.05)$ in bone mineral density (BMD) in subjects who regularly exercised above their anaerobic threshold over a 7-month period, while those who exercised below their anaerobic threshold experienced a slight but non-significant reduction. This outcome may reflect the greater $\mathrm{GH}$ response to exercise above the anaerobic threshold and the consequent circulating growth factor-mediated effects. Alternatively, the increased BMD in those subjects working above the anaerobic threshold may be a result of inducing acute metabolic acidosis with each exercise session. High-intensity exercise that induces acidosis can influence mineral homeostasis via two mechanisms.

\section{Renal calcium handling}

A reduction in $\mathrm{pH}$ brought about by metabolic acidosis reduces the reabsorption of $\mathrm{Ca}$ in the renal tubules, thereby increasing urinary $\mathrm{Ca}$ excretion and reducing blood $\mathrm{Ca}$. $\mathrm{Blood} \mathrm{Ca}$ is the predominant regulator of parathyroid gland activity. Parathyroid hormone (PTH) is secreted at the onset 
of hypocalcaemia. Osteolysis, a process that facilitates the movement of $\mathrm{Ca}$ ions from the bone fluid into the circulation, is activated within minutes. If PTH secretion is maintained for $\leq 1 \mathrm{~h}$, osteoclast lining cell activity is increased, while chronic ( $\leq 24 \mathrm{~h})$ PTH action on bone results in an increase in osteoclast number as well as activity. When administered intermittently PTH has been shown to have an anabolic effect on skeletal tissue that may act through a direct mechanism independent of resorption action (for review, see Morley et al. 1997). In animal studies intermittent PTH administration has been shown to stimulate bone formation, increase existing trabecular bone mass, increase osteoblast number and increase apposition rates (Whitfield et al. 1996). It should be noted, however, that PTH administration cannot replace lost trabeculae, and therefore the effectiveness of PTH action will decrease with increasing trabecular loss.

Ashizawa et al. (1997) reported that a single bout of highintensity resistance training increased blood lactate levels for $\leq 45 \mathrm{~min}$ post exercise, with an associated decrease in urinary $\mathrm{pH}$ over the same time period. An increase in fractional Ca excretion was also observed. A non-significant increase in PTH immediately post exercise that returned to baseline by $105 \mathrm{~min}$ post exercise was also reported. Takada et al. (1998), however, demonstrated that a marked increase in intact PTH $15 \mathrm{~min}$ after an anaerobic exercise challenge significantly increased blood lactate levels $(P<0 \cdot 05)$. It may well be that the increase in PTH in the study by Ashizawa et al. (1997) was missed due to the timing of sampling. This intermittent increase in PTH $(15 \mathrm{~min}-\leq 105 \mathrm{~min})$ in response to an acute anaerobic exercise bout may have a long-term anabolic effect on BMD, as reported by Hatori et al. (1993).

\section{Non-cellular physio-chemical bone dissolution}

Bone also appears to be instrumental in the maintenance of a stable physiological systemic $\mathrm{pH}$ during metabolic acidosis via non-cellular-mediated mechanisms. The alkaline salts of $\mathrm{Ca}$ in bone (carbonate and phosphate) can be mobilized for the defence of blood $\mathrm{pH}$, thereby releasing $\mathrm{Ca}$ in the process. In vitro studies demonstrated that the influx of protons from the extracellular fluid into bone took place along with the efflux of $\mathrm{Ca}$ from the bone into the circulation in both acute and chronic metabolic acidosis (Bushinsky et al. 1987; Bushinsky \& Sessler 1992; Bushinsky \& Frick, 2000). It is probable that this efflux of $\mathrm{Ca}$ facilitates the suppression of PTH by $105 \mathrm{~min}$ after an acute anaerobic challenge, thereby promoting the intermittent action of PTH.

\section{Effects of growth hormone on skeletal tissue}

It has been postulated that the most important way in which pituitary GH exerts its somatogenic effects on target tissues is by stimulating the release of a direct-acting insulin-like growth factor I from the liver. The insulin-like growth factor family as a whole plays an important role in the regulation of skeletal metabolism, the details of which have been documented elsewhere (for review, see Rosenfeld \& Roberts, 1999).
Thus, the original MES theory proposed by Frost (1987) has since been modified to account for the other osteogenic factors detailed earlier, i.e. distribution and rate as well as the non-mechanical influences (i.e. hormonal) on remodelling control. The MES-related stimulus theory encompasses all these variables (Lanyon, 1996).

\section{Measuring the properties of bone}

\section{Bone mass}

In order to quantify the effects of $\mathrm{PA}, \mathrm{Ca}$ or other interventions on bone, scientists have developed ways of describing the size, shape, strength and metabolic activity of bone. Commonly, dual-energy x-ray absorptiometry (DEXA) is used to describe the bone mineral content and BMD. Bone mineral content represents the total mass $(\mathrm{g})$ of bone mineral as hydroxyapatite within a measured bone region. BMD represents the mass of bone mineral per unit bone area scanned $\left(\mathrm{g} / \mathrm{cm}^{2}\right)$. Indeed, the term BMD is more correctly described as areal density, since DEXA measures mass per unit area, not mass per unit volume, and density is defined in physics as mass per unit volume. The difference between bone mineral content and BMD is important when comparing individuals of different size, as larger individuals will have more bone mineral but not necessarily a greater BMD. While DEXA provides a precise assessment of bone mass, it does not assess the architecture of bone (i.e. the number, connectivity and orientation of trabeculae), or cortical:trabecular bone at any given site. Nonetheless, bone mass as measured by DEXA explains almost $90 \%$ of the variance in the breaking strength of bone (Kanis, 1994). DEXA measurements have good short-term precision and long-term reliability, expressed as the CV. Although there are some differences between manufacturers, the in vivo precision is generally $0.5-1.5 \%$ for the lumbar spine and 1-2\% for the proximal femur (Khan et al. 2001). It is useful to consider these values in light of the expected changes in bone mass following PA or Ca interventions.

It is also important to consider the bone remodelling that is transient in studies involving $\mathrm{Ca}$ supplementation or exercise. At remodelling sites a temporary loss of bone occurs during the resorption period (the remodelling space). This bone is not measured by DEXA, so bone density measurements during the remodelling phase will underestimate the amount of bone tissue. Interventions that inhibit bone resorption, such as $\mathrm{Ca}$ supplementation or exercise, will cause fewer new sites to be activated and a decrease in the remodelling space, while previously-activated sites will continue to mineralize normally. This response causes an apparent increase in the amount of bone mineral measured, which will level off when the previously-activated sites finish the remodelling cycle. When the dietary or exercise intervention is removed, resorption will recommence and the remodelling space will increase, causing a transient decrease in the measured amount of bone mineral. Thus, it is important to consider changes occurring in the first remodelling cycle of an intervention separately from those occurring after this time. Studies should thus be of at least 6 months duration, or longer, depending on the individual's rate of bone turnover. 


\section{Bone remodelling}

While bone mass or density are useful measures, an individual's BMD is in fact representative of the lifelong remodelling profile and, therefore, the strength of the bone. It does not give any indication of the dynamics within the skeletal remodelling cycle at any particular time, i.e. whether bone is being accrued or lost. A further limitation to this method of evaluation is the lack of sensitivity associated with it. It may take $\leq 2$ years in most circumstances to be certain with $95 \%$ confidence that any change in BMD is more than can be accounted for by method imprecision. Consequently, the monitoring of interventions using measurement of BMD alone is quite slow. Over the past decade, however, advances have been made in the development of biochemical markers of skeletal cellular activity. To date a number of specific and sensitive markers have been identified, most notably the pyridinium cross-links of type I collagen of bone and the non-collagenous protein osteocalcin, which are representative of osteoclast and osteoblast activity respectively. The serum-based cross linked C-telopeptide (CTx) assay, which recognizes peptides comprising part of the C-terminal telopeptides, is also widely used as a resorption marker. These markers have been shown to be more sensitive to changes in skeletal tissue in response to intervention strategies than the measurement of BMD, and are thus widely used today. The measurement of biochemical markers specific for bone remodelling may also provide useful information about the mechanisms underlying the effect of PA and $\mathrm{Ca}$ on bone. The present paper will review the known effect(s) of PA and $\mathrm{Ca}$ on bone remodelling as measured by specific biochemical makers.

\section{What is the effect of physical activity and calcium on bone mass?}

\section{Meta-analytical studies of physical activity and bone mass}

Biological mechanisms indicate that exercise increases bone mass, and animal models clearly demonstrate the optimal forms of exercise to enhance bone mass (Lanyon, 1992; Turner \& Robling, 2003). Most cross-sectional studies have also described greater bone mass in athletes or active individuals compared with non-active controls (Forwood \& Burr, 1993), but, in spite of this evidence, the results of randomized controlled clinical trials in human subjects have been equivocal (Ernst, 1998). It is useful to try and quantify the magnitude of the effect of PA on BMD. Meta-analysis is a quantitative approach in which individual study findings addressing a common problem are statistically integrated and analysed. Inclusion criteria are stated and effect sizes (ES) calculated. ES is generally calculated by subtracting the outcome in the exercise group from the outcome in the control group and dividing this difference by the pooled SD of the exercise and control groups (Hedges \& Odkin, 1985). In general, an ES of about 0.50 is considered moderate (i.e. the exercise group differed from the control group by $0.5 \mathrm{SD}$ in favour of the exercise group), and an ES of $>0.70$ is considered large (Kelley et al. 2000), so the exercise group would do better than about $69 \%$ of the control group. Most studies calculate percentage changes to enhance interpretation. Study quality scores are also calculated based on factors such as bias, randomization and dropout. Kelley et al. (2000) have reported that studies with higher quality scores tend to report smaller measures of effect.

One such meta-analysis (Kelley, 1998a) examined the effect of controlled trials of aerobic exercise on hip BMD in post-menopausal women who were not receiving hormonereplacement therapy. A total of eighteen ES were derived from six studies. The average ES was 0.43 , equivalent to an overall change in BMD of $2.42 \%$ (exercise $+2 \cdot 13 \%$, non-exercise $-0 \cdot 29 \%$ ). Another meta-analytical review of randomized trials by the same author (Kelley, 1998b) included all exercise types and reported that both aerobic and strength training enhanced regional BMD. Mean changes were 1.62 and $0.65 \%$ for aerobic and strength training respectively. These findings are similar to those from another recent review of randomized controlled trials that reported mean changes of $1.79 \%$ in spine BMD (Bonainti et al. 2002). A review of resistancetraining studies in pre- and post-menopausal women included twenty-nine randomized and non-randomized trials (Kelley et al. 2001). ES for femur, lumbar spine and radius BMD were generally small $(<0 \cdot 30)$, were not statistically significant at the femur and equated to increases at the spine and radius in exercisers of 0.33 and $1.22 \%$ respectively, with decreases for controls of 0.05 and $0.95 \%$ respectively. At all sites increases with resistance training were greater for post-menopausal women than for premenopausal women. A recent review, in which individual patient data were used rather than summary means from key studies (thirteen trials, 699 subjects), indicated an exercise benefit of approximately $2 \%$ in lumbar spine BMD (exercise $+1 \%$, control $-1 \%$; Kelley et al. 2002). In men the exercise benefit was approximately $2 \cdot 6 \%$ (exercise $+2 \cdot 1 \%$, control $-0.5 \%$; Kelley et al. 2000) when BMD sites assessed were specific to the sites loaded.

In summary, meta-analytical studies suggest that exercise may have a beneficial effect on bone mass, and the benefit is in the order of $2-3 \%$. This effect is modest, particularly in light of the precision of the measurement tool, DEXA, which is between 0.5 and $2.0 \%$. Animal studies would suggest that resistance exercise might be particularly beneficial, but prospective trials in human subjects have been disappointing. Kelley (1998b) suggested that it is prudent to recommend exercise in combination with both adequate $\mathrm{Ca}$ intake and adequate oestrogen exposure for maintaining and/or increasing BMD in those at risk of osteoporosis. The exercise response is curvilinear, i.e. the greatest gains will be seen in those who are least active, and the effect is attenuated for more active individuals.

\section{Jumping exercise and bone mass}

As described previously, evidence from work with animals indicates that brief rapid-onset high-intensity strains will produce a maximal osteogenic response. Transferring this concept to human subjects it would appear that jumping would be an ideal mode of exercise. Bassey et al. (1998) reported ground reaction forces of three times body weight in pre- and post-menopausal women jumping fifty times daily (100 strain reversals at an average jump height of $80 \mathrm{~mm}$ (3 in)). Indeed, direct measurements of ground 
reaction forces in patients with instrumented hip prostheses suggest that jumping generates compressive forces in the hip that are about twice that of the ground reaction forces (Bassey et al. 1997). Thus, the jumping programme described by Bassey et al. (1998) was similar to animal studies in that it involved unusual strains with a comparable magnitude strain of onset $(1 \mathrm{~Hz})$ and number and rate of cycles. The jumping exercise, which lasted about $2 \mathrm{~min} / \mathrm{d}$, generated forces above the MES.

After 5 months of jumping on $6 \mathrm{~d}$ /week the premenopausal group ( $n$ 30) experienced a significant increase $(P<0.05)$ of $2-8 \%$ in femoral BMD compared with controls ( $n$ 26). However, in the post-menopausal group there was no significant difference between the exercise ( $n$ 69) and control ( $n$ 54) groups after 12 or 15 months, and no effect of hormone-replacement therapy on the outcome, despite the excellent compliance (median 91 (inter-quartile range 13) \%) and ground reaction forces that were four times body weight. During more prolonged endurance exercise programmes there is usually an endocrine as well as a mechanical strain response, and the authors suggested that perhaps post-menopausal women have a greater need than young women for this priming factor.

In a recent investigation of a small group of fifty-six pre-and post-menopausal women assigned to either a vertical-jumping exercise group or a no-exercise control group for 6 months, Sugiyama et al. (2002) made a similar finding. Among the premenopausal women hip BMD in the exercise group increased significantly compared with controls $(P<0.05)$, but there was no difference between these groups for the post-menopausal women. Turner et al. (1995), in work on rats, also found that a higher level of strain is necessary to activate formation in old bone compared with young bone. In this study oestrogen was found to enhance the osteogenic response to mechanical loading, and Kohrt et al. (1998) found that oestrogen preserved the BMD response after training.

However, this effect has not been observed in another animal study. A recent exercise training study in middleaged ovariectomized rats and sham rats illustrated that jump-exercised rats (jumped ten times daily on $5 \mathrm{~d} /$ week for 8 weeks $)$ had significantly $(P<0.05)$ increased tibial bone mass, strength and cortical areas compared with sedentary control rats (Honda et al. 2003). The bone mass and strength of ovariectomized rats increased similarly to that of the sham rats, despite oestrogen deficiency or osteopenia.

\section{Calcium}

For any individual the quality and amount of bone is dependent on events throughout that individual's lifespan. According to Heaney et al. (2000) the full genetic potential for bone mass is achieved by an individual when the skeleton is of a size and mass that has not been restricted by an insufficient supply of nutrients and/or sub-optimal mechanical loading. Bone mass is limited but not controlled by diet, but bone mass is regulated by mechanical loading (Heaney et al. 2000).

$\mathrm{Ca}$ has been described as a 'threshold' nutrient, i.e. skeletal accumulation varies with intake below the threshold, and above it skeletal accumulation remains constant. Children and adolescents appear to have an ability to adapt to low levels of Ca intake (Bailey et al. 2000), but Ca supplementation can help increase bone mass. A recent review of childhood $\mathrm{Ca}$ supplementation trials indicates that bone mass at predominantly cortical sites is increased with additional Ca (Specker \& Wosje, 2001). In seven studies of children it was found that $\mathrm{Ca}$ supplementation increased bone mineral by 1-3\% (Khan et al. 2001), but with the exception of one study the benefits disappeared after withdrawal of supplementation. In adulthood, studies suggest that dietary $\mathrm{Ca}$ may have a smaller effect than genetic or other environmental factors. In the early post-menopausal period $\mathrm{Ca}$ supplementation can have a positive effect on bone mass (Devine et al. 1997) and may help maintain but not increase bone mass in the later post-menopausal period (Khan et al. 2001).

\section{What is the effect of physical activity and calcium on bone turnover?}

Skeletal tissue responds to changes in its environment via modifications to the remodelling cycle, which can be measured by specific biochemical markers. Biochemical markers of bone turnover are, however, subject to sources of variance, i.e. pre-analytical, within-run analytical and withinsubject biological $\left(\mathrm{CV}_{\mathrm{I}}\right)$. The major source of variance, $\mathrm{CV}_{\mathrm{I}}$, cannot be eliminated and must be established for each biochemical marker to determine a biologically-significant change. To date, both the short-term (days to weeks) and the long-term (months) $\mathrm{CV}_{\mathrm{I}}$ of biochemical markers of bone turnover have been reported by several authors (Beck-Jensen et al. 1992; Colwell et al. 1993; Blumsohn et al. 1994; Panteghini \& Pagani, 1995, 1996; Popp-Snijders et al. 1996; Ginty et al. 1998b; Orwoll et al. 1998; Plebani et al. 2000; Scariano et al. 2001). These studies report a lower $\mathrm{CV}_{\mathrm{I}}$ in markers of bone formation (osteocalcin 5-9\%, type I procollagen peptide $6.2 \%$, bone specific alkaline phosphatase $<6 \%$ ) than in those of resorption, and a lower $\mathrm{CV}_{\mathrm{I}}$ in serum markers of bone resorption (CTX and crosslinked N-telopeptides; $<8 \%$ and $10.7 \%$ respectively, tartrate-resistant acid phosphatase; $5 \cdot 2 \%$ ) than their urinary counterparts (cross-linked N-telopeptides $17 \%$, deoxypyridinoline $24 \%$, pyridinoline $21 \%$, tartrate-resistant acid phosphatase $12 \cdot 7 \%$ ).

The efficacy of biochemical markers to respond to longterm ( $>6$ months) changes in cellular activity post exercise has been previously demonstrated (Bennell et al. 1997). Exercise intensities above the remodelling threshold have been reported to uncouple the remodelling cycle in favour of formation and/or reduce the overall rate of remodelling, which has a long-term anabolic effect on skeletal tissue. Non-weight-bearing exercise does not appear to impact on the remodelling cycle, and there is, therefore, little difference in measures of bone strength between such athletes (cyclists and swimmers) and their sedentary counterparts. Long-term studies, however, have traditionally looked at populations and the group mean effect of the intervention. There is evidence to suggest that the effect of the intervention at an individual level may vary considerably from the group effect. To date, however, there are few 
studies that have looked at acute (days) changes in bone turnover after an intervention. There are a number of studies that have looked at the effect of exercise on specific markers of bone turnover in the hours and days post exercise. The exercise modalities varied between studies from highresistance exercise (Menkes, 1993; Ashizawa et al. 1997, 1998; Fujimura et al. 1997; Rong et al. 1997) to highintensity cycle ergometry (Brahm et al. 1997; Rong et al. 1997) to low-intensity treadmill running (Nishiyama et al. 1988; Rong et al. 1997; Welsh et al. 1997). The sampling times varied between studies from immediately post exercise to $\leq 72 \mathrm{~h}$ post exercise. In all studies, however, samples were only collected on the day before the exercise bout (either single or sequential samples to account for the diurnal rhythm) and no account was made for the inherent variability of the specific biochemical markers. It is not surprising, therefore, that inconsistencies exist among the data reported. In fact, one group replicated a study using the same subject group but extended the sampling period post intervention and found conflicting results (Fujimura et al. 1997; Ashizawa et al. 1998). In nutritional intervention studies using biochemical markers $\mathrm{Ca}$ supplementation has been shown to decrease bone resorption in the long-term (i.e. $<2-4$ years) in post-menopausal women (McKane et al. 1996; Riggs et al. 1998). Decreased bone resorption has also been observed in the short term (i.e. after allowing at least 2 weeks to stabilize after a change in dietary $\mathrm{Ca}$ intake) in early post-menopausal women
(Scopacasa et al. 1998) and in young adults (Ginty et al. 1998a).

In order to determine whether a change in a biochemical marker of bone turnover post intervention is truly biologically significant the $\mathrm{CV}_{\mathrm{I}}$ of that marker must first be established and the critical difference (CD; defined as the minimum significant difference $(P=0.05)$ between any measurement of a quantity against a baseline mean value of the same quantity) calculated.

The $\mathrm{CV}_{\mathrm{I}}$ and $\mathrm{CD}(P=0 \cdot 05)$ for osteoclacin, serum CTx and urinary total deoxypyridinoline of twenty-two subjects (ten males aged 23-35 years and twelve post-menopausal females not on hormone-replacement therapy aged 45-63 years) established over a period of five consecutive days are presented in Table 1 (P Carroll, P Jakeman, N Murphy, M Loughnane, R Donnelly, D Barry and E Barrett, unpublished results). The $\mathrm{CV}_{\mathrm{I}}$ were found to be heterogeneous for all biochemical markers measured for both the male and the female group. Thus, the group mean CD could not be applied to determine a biologically-significant change for each individual within the group. The large ranges of CD presented in Table 1 are evidence of this situation. The CD of osteocalcin varied $\leq 17$-fold between subjects despite being the most stable biochemical marker measured in this study. Consequently, while a $2 \cdot 1 \%$ change in osteocalcin was indicative of a significant perturbation in cellular function for subject no. 10, a $33 \cdot 6 \%$ change was required to achieve the same outcome for subject no. 3. Thus, biological

Table 1. The within-subject biological variance $\left(\mathrm{CV}_{1} ; \%\right)$ and critical difference* $(\mathrm{CD} ; \%)$ for osteocalcin (OC), serum cross-linked C-telopeptides (sCTx) and urinary total deoxypyridinoline (dPyr) for twenty-two subjects (twelve post-menopausal females not on hormone-replacement therapy (subjects nos. 1-12) aged 45-63 years and ten males (subjects nos. 13-22) aged 23-35 years established over a period of five consecutive days $†$

\begin{tabular}{|c|c|c|c|c|c|c|}
\hline \multirow[b]{2}{*}{ Subject no. } & \multicolumn{2}{|c|}{$\mathrm{OC}(\mathrm{ng} / \mathrm{ml})$} & \multicolumn{2}{|c|}{ sCTx $(n g / m l)$} & \multicolumn{2}{|c|}{$24 \mathrm{~h}$ urinary total $\mathrm{dPyr}(\mathrm{nmol} / \mathrm{d})$} \\
\hline & $\mathrm{CV}_{\mathrm{I}}$ & $C D$ & $\mathrm{CV}_{\mathrm{I}}$ & $C D$ & $\mathrm{CV}_{1}$ & $C D$ \\
\hline 1 & $7 \cdot 2$ & $15 \cdot 5$ & $10 \cdot 0$ & $21 \cdot 5$ & $24 \cdot 7$ & $54 \cdot 0$ \\
\hline 2 & $3 \cdot 4$ & $7 \cdot 6$ & $2 \cdot 8$ & $6 \cdot 7$ & $12 \cdot 8$ & $29 \cdot 5$ \\
\hline 3 & $15 \cdot 7$ & $33 \cdot 6$ & $7 \cdot 7$ & $16 \cdot 7$ & $29 \cdot 0$ & $65 \cdot 9$ \\
\hline 4 & $2 \cdot 9$ & $6 \cdot 3$ & $9 \cdot 6$ & $20 \cdot 9$ & $19 \cdot 6$ & $42 \cdot 3$ \\
\hline 5 & $7 \cdot 3$ & $15 \cdot 8$ & $17 \cdot 6$ & $37 \cdot 8$ & $25 \cdot 7$ & $55 \cdot 5$ \\
\hline 6 & $6 \cdot 8$ & $14 \cdot 8$ & $11 \cdot 1$ & $25 \cdot 2$ & ND & ND \\
\hline 7 & $2 \cdot 6$ & $5 \cdot 8$ & $11 \cdot 3$ & $25 \cdot 2$ & $35 \cdot 8$ & $77 \cdot 8$ \\
\hline 8 & $2 \cdot 1$ & $4 \cdot 7$ & $9 \cdot 4$ & $21 \cdot 1$ & $9 \cdot 7$ & $21 \cdot 1$ \\
\hline 9 & $13 \cdot 7$ & $29 \cdot 5$ & $5 \cdot 0$ & $10 \cdot 9$ & $45 \cdot 8$ & 98.9 \\
\hline 10 & 0.9 & $2 \cdot 1$ & $7 \cdot 5$ & $16 \cdot 6$ & $10 \cdot 9$ & $37 \cdot 0$ \\
\hline 11 & $3 \cdot 5$ & $7 \cdot 6$ & $10 \cdot 3$ & $22 \cdot 6$ & $22 \cdot 3$ & $48 \cdot 7$ \\
\hline 12 & $1 \cdot 2$ & $3 \cdot 6$ & $4 \cdot 4$ & $9 \cdot 8$ & $41 \cdot 4$ & $90 \cdot 5$ \\
\hline 13 & 4.5 & $9 \cdot 8$ & $6 \cdot 4$ & $13 \cdot 9$ & $17 \cdot 9$ & $39 \cdot 2$ \\
\hline 14 & $5 \cdot 3$ & 11.9 & $10 \cdot 5$ & $23 \cdot 0$ & $33 \cdot 2$ & $72 \cdot 1$ \\
\hline 15 & 3.9 & 8.5 & $5 \cdot 8$ & $12 \cdot 8$ & $57 \cdot 4$ & $123 \cdot 4$ \\
\hline 16 & $5 \cdot 5$ & $11 \cdot 8$ & $9 \cdot 4$ & $20 \cdot 2$ & $12 \cdot 9$ & $30 \cdot 9$ \\
\hline 17 & $2 \cdot 6$ & $5 \cdot 7$ & $11 \cdot 4$ & 24.9 & $28 \cdot 2$ & $62 \cdot 1$ \\
\hline 18 & $5 \cdot 5$ & $12 \cdot 8$ & $9 \cdot 1$ & $19 \cdot 9$ & $43 \cdot 4$ & 93.4 \\
\hline 19 & $3 \cdot 0$ & $7 \cdot 4$ & $5 \cdot 8$ & $14 \cdot 0$ & $45 \cdot 9$ & $98 \cdot 7$ \\
\hline 20 & $1 \cdot 8$ & 4.9 & 4.5 & $10 \cdot 7$ & $52 \cdot 8$ & $113 \cdot 3$ \\
\hline 21 & $3 \cdot 2$ & $8 \cdot 6$ & $7 \cdot 8$ & $17 \cdot 0$ & $44 \cdot 6$ & $95 \cdot 7$ \\
\hline 22 & $4 \cdot 4$ & $9 \cdot 5$ & $14 \cdot 5$ & $31 \cdot 1$ & $64 \cdot 6$ & $139 \cdot 1$ \\
\hline Mean & 4.9 & $10 \cdot 8$ & 8.7 & $19 \cdot 2$ & $32 \cdot 3$ & 70.9 \\
\hline SD & $3 \cdot 7$ & $7 \cdot 7$ & 3.5 & $7 \cdot 3$ & $16 \cdot 0$ & $33 \cdot 3$ \\
\hline Range & $0 \cdot 9-15 \cdot 7$ & $2 \cdot 1-33 \cdot 6$ & $2 \cdot 9-17 \cdot 6$ & $6 \cdot 7-37 \cdot 8$ & $9 \cdot 7-64 \cdot 6$ & $21 \cdot 0-139 \cdot 1$ \\
\hline
\end{tabular}

ND, not detectable.

${ }^{*}$ Minimum significant difference $(P=0.05)$ between any measurement of a quantity against a baseline mean value of the same quantity

†P Carroll, P Jakeman, N Murphy, M Loughnane, R Donnelly, D Barry and E Barrett (unpublished results). 
significance was defined as a relative change from the baseline mean that was greater than the individual $\mathrm{CD}\left(\mathrm{CD}_{\mathrm{I}}\right)$ established for each biochemical marker. However, relative changes following an intervention would not be comparable between subjects. In order to standardize observed changes post intervention between subjects the relative changes observed could be divided by the error term used in the calculation of $\mathrm{CD}_{\mathrm{I}}(\%)$, i.e.

$$
\begin{array}{ll}
\left(\mathrm{P} \times \sqrt{ }(1+1 / k) \times\left(\left(0.5 \times\left(\mathrm{CV}_{\mathrm{A}}\right)^{2}\right)+\left(\mathrm{CV}_{1}\right)^{2}\right)^{1 / 2} .\right. \\
(\text { multiplier at required } & (\text { error term }) \\
\text { level of probability) } &
\end{array}
$$

The error term encompasses both sources of variance specific for an individual (where $\mathrm{CV}_{\mathrm{A}}$ is the within-run analytical variance) and the difference in these combined errors must be accounted for in order to compare data between subjects. The confidence limits set by the multiplier can be established by multiplying the probability constant at the required level of probability $(P)$ by the square root of $(1+1 / k)$. The multiplication is necessary to accommodate the fact that a single data point following an intervention will be compared with a mean of $k$ baseline data points.

However, it cannot be assumed that the observed $5 \mathrm{~d}$ mean value is representative of true biological homeostasis. The extent of imprecision, $h$, between the observed mean and the true homeostatic set-point can be calculated at any level of probability at a fixed $k$ of $5 \mathrm{~d}$. By increasing $h$, however, the probability of committing a type II statistical error when defining a biologically-significant change increases $(h=1 / 2 \beta)$.

Using this template a study was carried out into whether changes in bone turnover could be observed following a discrete bout of high-intensity cycling using biochemical markers specific for bone formation and resorption. Following the $5 \mathrm{~d}$ control period subjects completed a $10 \mathrm{~d}$ exercise trial comprising $3 \mathrm{~d}$ of cycle ergometery (20 min at $10-20 \%$ above the anaerobic threshold) followed by $7 \mathrm{~d}$ of recovery. Relative changes from the baseline mean for both phases of the study were normalized for individual CD, and data for serum crosslaps (CTx) are presented in Fig. 1; a biologically-significant change is defined by any deviation $> \pm 2 \cdot 15(P=0 \cdot 05)$. It should be noted, however, that at this level of probability $h$ varies between subjects $(3-18 \%$; $\beta$ 6-36\%). Under these statistical conditions a significant perturbation was observed in $20 \%$ of the data (thirty-nine samples) and thirty-one of these samples (16\%) were perturbed in a negative direction, i.e. a reduction in osteoclast activity. However, the nature of the individual responses is highly varied with regard to the magnitude, the timing and the direction. The randomness seen in the serum CTx data is also apparent in both the osteocalcin and the $24 \mathrm{~h}$ urinary total deoxypyridinoline data. There are a number of factors that may influence the individual responses to the same relative exercise challenge. These factors include the genetic predisposition of the subject and the individual remodelling rates at different skeletal surfaces and anatomical sites before the intervention. These inconsistencies confound the interpretation of the data, and the physiological relevance of the data for any individual subject cannot, therefore, be resolved. The use of
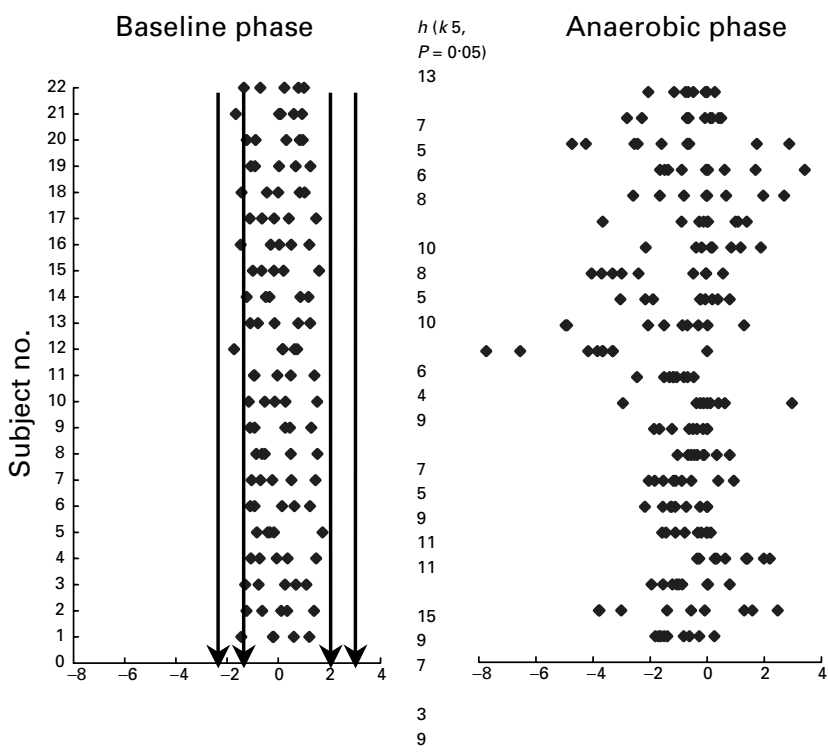

Multiplier $(2.15$ at $P=0.05)$

Fig. 1. Serum cross-linked C-telopeptide levels normalized for individual critical difference (minimum significant difference $(P=0.05)$ between any measurement of a quantity against a baseline mean value of the same quantity; for details of the calculation and the equation, see p. 835) for the baseline and exercise phases of the study ( $n$ 22; twelve post-menopausal females not on hormonereplacement therapy (subjects nos. 1-12) aged 45-63 years and ten males (subjects nos. 13-22) aged 23-35 years). The extent of imprecision, $\left(h^{1 / 2} \beta\right)$, was calculated for a sampling frequency of $5 \mathrm{~d}$ at $P=0.05 ; k$ is the no. of baseline points i.e., 5 days.

biochemical markers in an acute setting may best be elucidated once the relationships between changes in biochemical markers and BMD have been established.

Interestingly, when the group mean data for $1 \mathrm{~d}$ preexercise (baseline day 5) and $\leq 72 \mathrm{~h}$ post exercise were analysed using a Student's paired $t$ test no significant change in any marker measured was observed ( $t$ for the change was: osteocalcin $<0 \cdot 489$, serum CTx $<0 \cdot 171$, deoxypyridinoline $<0.526)$. It is apparent that this sampling frequency, as has been the norm in acute studies to date, is insufficient to identify the true impact of this exercise challenge on skeletal metabolism.

\section{Interactions between calcium and physical activity and their effect on bone}

According to a recent excellent review addressing the effect of PA on bone health (Khan et al. 2001), the question of whether $\mathrm{Ca}$ and PA interact synergistically was identified as one of the most important unanswered research questions in the area of lifestyle-related bone health research. To adequately determine whether $\mathrm{Ca}$ intake modifies the effect of PA on bone a $2 \times 2$ factorial design is needed with PA (yes or no) and Ca supplementation (yes or no) as the two main factors.

Specker (1996) undertook a review of all intervention trials reporting the effects of PA on bone mass, and also 
those reporting mean $\mathrm{Ca}$ intakes. A total of sixteen studies were identified, most of which involved peri- or postmenopausal women, with sample sizes ranging from five to 130 per group. The report provides indirect evidence that the beneficial effect of increased PA on bone may only be apparent at high $\mathrm{Ca}$ intakes $(>1000 \mathrm{mg} / \mathrm{d})$, with no effect at mean $\mathrm{Ca}$ intakes of $<1000 \mathrm{mg} / \mathrm{d}$. This modifying effect was more pronounced in the lumbar spine, the weight-bearing region, than in the radius. Similarly, a meta-analysis by Kelley (1998a) examining the effect of aerobic exercise on bone mass found larger ES among subjects consuming $>1000 \mathrm{mg} \mathrm{Ca} / \mathrm{d}(0.83) v$. those consuming $<1000 \mathrm{mg} / \mathrm{d}$ $(-0.23)$. In animals low $\mathrm{Ca}$ intake or reduced $\mathrm{Ca}$ bioavailability may limit the bone's response to exercise training (Lanyon et al. 1986).

Very recently, however, two longitudinal trials have been published that attempt to answer this question. Specker \& Binkley (2003) conducted a 1-year randomized placebocontrolled partially-blinded trial of PA and $\mathrm{Ca}$ supplementation in 239 children aged 3-5 years. Children were randomized to a $\mathrm{Ca}(1000 \mathrm{mg} / \mathrm{d})$-supplementation group or a placebo group, and to a gross motor activity group or fine motor activity group. The gross motor activity group received $30 \mathrm{~min}$ activities ( $5 \mathrm{~min}$ warm-up, $20 \mathrm{~min}$ jumping, skipping and hopping, $5 \mathrm{~min}$ cool-down $/ \mathrm{d}$, while the fine motor group did $30 \mathrm{~min}$ seated activities/d. The authors found no positive effect of PA on changes in leg bone mass unless the children were consuming high $\mathrm{Ca}$ intakes $(>1100 \mathrm{mg} / \mathrm{d})$, which is consistent with the results of the meta-analysis of adult activity trials discussed earlier (Specker, 1996).

The second study employing a $2 \times 2$ factorial design was also conducted in young children (Iuliano-Burns et al. 2003). Sixty-six girls aged $8 \cdot 8($ SE $0 \cdot 1)$ years were randomly assigned to one of four study groups for 8.5 months, i.e. moderate-impact exercise with or without $\mathrm{Ca}$, or low-impact exercise with or without $\mathrm{Ca}$. Mean baseline $\mathrm{Ca}$ intakes for all groups were low (approximately $680 \mathrm{mg} / \mathrm{d} ; 75 \%$ had intakes below the recommended daily intake). The moderate-impact group exercised three times weekly for 20 min (hopping, skipping and jumping activities producing ground reaction forces between two and four times body weight), whereas the low-impact group did stretching and low-impact dance routines at the same frequency and duration. $\mathrm{Ca}$ supplementation took the form of food fortification with milk minerals (434 (SE 19) mg/d). Bone mass measurements were assessed by DEXA. A significant exercise-Ca interaction was found at the femur $(7 \cdot 1 \%$; $P<0 \cdot 05$ ). At the loaded site (tibia-fibula) there was no exercise-Ca interaction, but there was an exercise effect, with a $3 \%$ greater increase in the high-impact group $v$. low-impact group. At non-loaded sites (humerus and ulnaradius) bone mineral content increased $2-4 \%$ more in the supplemented groups than in the unsupplemented groups. The authors conclude that greater gains in bone mass at loaded sites may be achieved when short bouts of moderate exercise are combined with increased $\mathrm{Ca}$ intake, and that the former confers region-specific effects and the latter produces generalized effects. This suggestion that $\mathrm{Ca}$ has a general effect on bone sites, even if they are unloaded, while greater PA preferentially increases the bone mass of loaded sites is supported by results of a recent cross-sectional study in a total of 218 pre- and post-menopausal women (Uusi-Rasi et al. 2002). High $\mathrm{Ca}$ intake was positively associated with non-weight-bearing radial bone characteristics (measured by quantitative computed tomography) whereas PA seemed to particularly benefit the weightbearing tibia.

An alternative hypothesis to the $\mathrm{PA}-\mathrm{Ca}$ interaction has been offered that suggests that high levels of daily PA may permit an adaptation to low $\mathrm{Ca}$ intakes. This suggestion comes from cross-sectional studies in Asian countries such as Hong Kong and Japan, where women have lower Ca intakes than in the USA, but lower rates of hip fracture exist (Anderson, 1999). Asian women also have lower lifetime total oestrogen exposures as a result of later age of menarche and earlier onset of menopause, both of which are influenced by the amount of accumulated body fat, which is typically lower in Asian females than in Western females. Anderson \& Sjoberg (2001) hypothesized that despite the beneficial effect of $\mathrm{Ca}$ in reducing PTH, other lifestyle factors, such as regular PA, must be able to overcome the adverse effects of PTH on bone loss. It may also be, however, that other dietary factors, such as increased vitamin D status from fish consumption and sunlight exposure and phyto-oestrogens from soyabean products, compensate for the low $\mathrm{Ca}$ intake seen in Asian women (Anderson, 1999).

In summary, the mechanism by which the combination of $\mathrm{Ca}$ and exercise produces a better effect on bone than either intervention alone is not understood. Further $2 \times 2$ factorial studies are necessary, as are interventions employing measurement techniques designed to assess bone geometry as well as bone mass. Studies using biochemical markers could help elucidate mechanisms, but there are serious concerns about the current practice in PA and nutrition research of utilizing $1 \mathrm{~d}$ baseline measurements as representative of homeostasis. Whilst biochemical markers are sensitive to acute challenges, the longitudinal relationship between changes in biochemical markers and BMD needs to be explored to help explain the biological relevance of the acute response.

\section{References}

Anderson JJB (1999) Plant-based diets and bone health: nutritional implications. American Journal of Clinical Nutrition 70, Suppl. 3, 539S-542S.

Anderson JJB \& Sjoberg HH (2001) Dietary calcium and bone health in the elderly: uncertainties about recommendations. Nutrition Research 21, 263-268.

Ashizawa N, Fujimura R, Tokuyama K \& Suzuki M (1997) A bout of resistance exercise increases urinary calcium independently of osteoclastic activation in men. Journal of Applied Physiology $\mathbf{8 3}$, $1159-1163$.

Ashizawa N, Ouchi G, Fujimura R, Yoshida Y, Tokuyama K \& Suzuki M (1998) Effects of a single bout of resistance exercise on calcium and bone metabolism in untrained young males. Calcified Tissue International 62, 104-108.

Bailey DA, Martin AD, McKay HA, Whiting S \& Mirwall R (2000) Calcium accretion in girls and boys during puberty: a longitudinal analysis. Journal of Bone and Mineral Research 15, 2245-2250. 
Bassey EJ, Littlewood JJ \& Taylor SJG (1997) Relations between ground reaction forces, compressive axial forces in an instrumental massive femoral implant and integrated electromyographs from Vastus lateralis during various osteogenic exercises. Journal of Biomechanics 30, 213-223.

Bassey EJ, Rothwell MC, Littlewood JJ \& Pye DW (1998) Pre- and post-menopausal women have different bone mineral density responses to the same high-impact exercise. Journal of Bone and Mineral Research 13, 1805-1813.

Beck Jensen JE, Kollerup G, Sorensen HA, Pors Nielsen S \& Sorensen $\mathrm{OH}$ (1992) A single measurement of biochemical markers of bone turnover has limited utility in the individual person. Scandinavian Journal of Clinical and Laboratory Investigation 57, 351-360.

Bennell KL, Malcom SA, Khan KM, Thomas SA, Reid SJ, Brukner PD, Ebling PR \& Wark JD (1997) Bone mass and bone turnover in power athletes, endurance athletes, and controls: A 12-month longitudinal study. Bone 20, 477-484.

Blumsohn A, Hannon RA, Al-Dehaimi AW, Colwell A \& Eastell R (1994) Short-term intraindividual variability of markers of bone turnover in healthy adults. Journal of Bone and Mineral Research 9, S153.

Bonainti D, Shea B, Iovine R, Negrini S, Robinson V, Kemper HC, Wells G, Tugwell P \& Cranney A (2002) Exercise for preventing and treating osteoporosis in postmenopausal women (Cochrane Raiser). The Cochrane Library Issue 4. Oxford: Update Software.

Brahm H, Piehl-Aulin K \& Ljunghall S (1997) Bone metabolism during exercise and recovery; the influence of plasma volume and physical fitness. Calcified Tissue International 62, 192-198.

Burr DB \& Martin RB (1992) Mechanism of bone mineral adaptation of the mechanical environment. Sandoz Journal of Medical Science 31, 59-76.

Bushinsky DA \& Frick KK (2000) The effects of acid on bone. Current Opinion in Nephrology and Hypertension 9, 369-379.

Bushinsky DA, Krieger NS, Geisser DI Grossman EB \& Coe FL (1987) Mechanism of proton-induced bone calcium release: calcium carbonate dissolution. American Journal of Physiology 250, F1090-F1097.

Bushinsky DA \& Sessler NE (1992) Critical role of bicarbonate in calcium release from bone. American Journal of Physiology 263, F510-F515.

Carter DR (1987) Mechanical loading history and skeletal biology. Journal of Biomechanics 20, 1095-1109.

Colwell A, Russell RG \& Eastell R (1993) Factors affecting the assay of urinary 3-hydroxy pyridinium crosslinks of collagen as markers of bone resorption. European Journal of Clinical Investigation 23, 341-349.

Cuneo RC \& Wallace JD (1994) Growth hormone, insulin-like growth factors and sport: review. Endocrinology and Metabolism 1, 3-13.

Devine A, Dick IM, Heal SJ, Criddle RA \& Prince RL (1997) A 4-year follow-up study of the effect of calcium supplementation on bone density in early postmenopausal women. Osteoporosis International 7, 23-24.

Ernst E (1998) Exercise for female osteoporosis. A systematic review of randomised clinical trials. Sports Medicine 25, 359-368.

Fesling NE, Brasel JA \& Cooper DM (1992) Effect of low and high intensity exercise on circulating growth hormone in men. Journal of Clinical Endocrinology and Metabolism 75, 157-162.

Forwood MR \& Burr DB (1993) Physical activity and bone mass: exercises in futility? Bone and Mineral 21, 89-112.

Frost HM (1987) The Mechanostat: A proposed pathogenic mechanism of osteoporosis and the bone mass effects of mechanical and non-mechanical agents. Journal of Bone and Mineral Research 2, 73-85.
Frost HM (1991) A new direction for osteoporosis research: a revival and proposal. Bone 12, 429-437.

Fujimura R, Ashizawa N, Watanabe M, Mukai N, Amagai H, Fukubayashi T, Hayashi K, Tokuyama K \& Suzuki M (1997) Effect of resistance exercise on training on bone formation and resorption in young male subjects assessed by markers of bone metabolism. Journal of Bone and Mineral Research 12, $656-662$.

Ginty F, Flynn A \& Cashman KD (1998a) The effect of short-term calcium supplementation on biochemical markers of bone metabolism in healthy young adults. British Journal of Nutrition 80, 437-443.

Ginty F, Flynn A \& Cashman K (1998b) Inter and intra-individual variations in urinary excretion of pyridinium crosslinks of collagen in healthy young adults. European Journal of Clinical Nutrition 52, 71-73.

Hatori M, Hasegawa A, Adachi H, Shinozaki A, Hayashi R, Okano H, Mizunuma H \& Murata K (1993) The effects of walking at the anaerobic threshold level on vertebral bone loss in post-menopausal women. Calcified Tissue International 52, 411-414

Heaney RP, Abrams S, Dawson-Hughes B, Looker A, Marcus R, Matkovic V \& Weaver C (2000) Peak bone mass. Osteoporosis International 11, 985-1009.

Hedges LV \& Odkin I (1985) Statistical Methods for Metaanalysis. San Diego, CA: Academic Press.

Honda A, Sogo N, Nagasawa S, Shimuzu T \& Umemura Y (2003) High-impact exercise strengthens bone in osteopenic ovariectomized rats with the same outcome as sham rats. Journal of Applied Physiology; abstract from the May issue available at: http://www.jap.physiology.org

Inman CL, Warren GL, Hogan HA \& Bloomfield SA (1999) Mechanical loading attenuates bone loss due to immobilisation and calcium deficiency. Journal of Applied Physiology 87, 189-195.

Iuliano-Burns S, Saxon L, Naughton G, Gibbons K \& Bass SL (2003) Regional specificity of exercise and calcium during skeletal growth in girls: a randomised controlled trial. Journal of Bone and Mineral Research 18, 156-162.

Kanis JA (1994) Osteoporosis. Oxford: Blackwell Science.

Kelley GA (1998a) Aerobic exercise and bone density at the hip in postmenopausal women: a meta-analysis. Preventive Medicine 27, 798-807.

Kelley GA (1998b) Exercise and regional bone mineral density in postmenopausal women: A meta-analytic review of randomised trials. American Journal of Physical Medicine and Rehabilitation 77, 76-87.

Kelley GA, Kelley KS \& Tran ZV (2000) Exercise and bone mineral density in men: a meta-analysis. Journal of Applied Physiology 88, 1730-1736.

Kelley GA, Kelley KS \& Tran ZV (2001) Resistance training and bone mineral density in women: A meta-analysis of controlled trials. American Journal of Physical Medicine and Rehabilitation 80, 65-77.

Kelley GA, Kelley KS \& Tran ZV (2002) Exercise and lumbar spine bone mineral density in postmenopausal women: A metaanalysis of individual patient data. Journal of Gerontology 57A, M599-M604.

Kelly PJ, Eisman JA \& Sambrook PN (1990) Interaction of genetic and environmental influences on peak bone density. Osteoporosis 1, 56-60.

Khan K, McKay H, Kannus P, Bailey D, Wark J \& Bennell K (2001) Physical Activity and Bone Health. Champaign, IL: Human Kinetics.

Kohrt WM, Ehsani AA \& Birge SJ (1998) HRT preserves increases in bone mineral density and reductions in body fat after a 
supervised exercise program. Journal of Applied Physiology 84, $1506-1512$.

Lanyon LE (1984) Functional strain as a determinant for bone remodelling. Calcified Tissue International 36, S56-S61.

Lanyon LE (1992) Control of bone architecture by functional loadbearing. Journal of Bone and Mineral Research 7, Suppl. 2, 5369-5375.

Lanyon LE (1996) Using functional loading to influence bone mass and architecture: objectives, mechanisms, and relationship with estrogen of the mechanically adaptive process in bone. Bone $\mathbf{1 8}$, S37-S43.

Lanyon LE, Goodship AE, Pye CJ \& MacFie JH(1982) Mechanically adaptive bone remodelling. Journal of Biomechanics 15, 141-154.

Lanyon LE, Rubin CT \& Boust G (1986) Modulation of bone loss during calcium insufficiency by controlled dynamic loading. Calcified Tissue International 38, 209-216.

McKane WR, Khosla S, Egan KS, Robins SP, Burritt MF \& Riggs BL (1996) Role of calcium intake in modulating age-related increases in parathyroid function and bone resorption. Journal of Clinical Endocrinology and Metabolism 81, 1699-1703.

Menkes C (1993) Strength training increases regional bone mineral density and bone remodelling in middle aged and older men. Journal of Applied Physiology 60, 2028-2034.

Morley P, Whitfield JF \& Willick GE (1997) Anabolic effects of parathyroid hormone on bone. Trends in Endocrinology and Metabolism 6, 225-231.

Nishiyama S, Tomoeda S, Ohta T, Higuchi A \& Matsuda I (1988) Differences in basal and post exercise osteocalcin levels in athletic and nonathletic humans. Calcified Tissue International 43, 150-154.

O'Connor JA \& Lanyon LE (1982) The influence of strain rate on adaptive bone remodelling. Journal of Biomechanics 15, 767-781.

Orwoll ES, Bell NH, Nanes MS, Flessland KA, Pettinger MB, Mallinal NJ \& Cain DF (1998) Collagen N-telopeptide excretion in men: the affects of age and intrasubject variability. Journal of Clinical Endocrinology and Metabolism 83, 3930-3935.

Panteghini M \& Pagani F (1995) Biological variation in bonederived biochemical markers in serum. Scandinavian Journal of Clinical and Laboratory Investigation 55, 609-616.

Panteghini M \& Pagani F (1996) Biological variation in urinary excretion of pyridinium crosslinks: recommendations of the optimum specimen. Annals of Clinical Biochemistry 33, 36-42.

Plebani M, Bernardi D, Meneghetti MF, Ujka F \& Zaninotto M (2000) Biological variability in assessing the clinical value of biochemical markers of bone turnover. Clinica Chimica Acta 299, 77-86.

Popp-Snijders C, Lips P \& Netelenbos JC (1996) Intra-individual variation in bone resorption markers in urine. Annals of Clinical Biochemistry 33, 347-348.

Prentice A (1997) Is nutrition important in osteoporosis? Proceedings of the Nutrition Society 56, 357-367.

Riggs L, O'Fallon M, Mulis J, O'Connor MK, Kumer R \& Melton L III (1998) Long-term effects of calcium supplementation on serum parathyroid hormone trial, bone turnover and bone loss in elderly women. Journal of Bone and Mineral Research 13, 168-174.

Robling AG, Burr DB \& Turner CH (2001) Recovery periods restore mechanosensitivity to dynamically loaded bone. Journal of Experimental Biology 204, 3389-3399.
Rong H, Berg U, Torring O, Sundberg CJ, Granberg B \& Bucht E (1997) Effect of acute endurance and strength exercise on circulating calcium regulating hormones and bone markers in young healthy males. Scandinavian Journal of Medicine and Science in Sports 7, 152-159.

Rosenfeld RG \& Roberts CT Jr (1999) The IGF System; Molecular Biology Physiology and Clinical Applications. Town, NJ: Humana Press.

Rubin CT \& Lanyon LE (1984) Regulation of bone formation by applied dynamic loads. Journal of Bone and Joint Surgery 66A, 397-402.

Scariano JK, Garry PJ, Montoya GD, Wilson JM \& Baumgartner RN (2001) Critical differences in the serial measurements of three biochemical markers of bone turnover in the sera of pre-and postmenopausal women. Clinical Biochemistry 34, 639-644.

Scopacasa F, Horowitz M, Wishart JM, Need AG, Morris HA, Wittert G \& Nordin BE (1998) Calcium supplementation suppresses bone resorption in early postmenopausal women. Calcified Tissue International 62, 8-12.

Specker B \& Binkley T (2003) Randomized trial of physical activity and calcium supplementation on bone mineral content in 3 to 5 year-old children. Journal of Bone and Mineral Research 18, 885-892.

Specker B \& Wosje K (2001) A critical appraisal of the insistence relating calcium and dairy intake to bone health early in life. In Nutritional Aspects of Osteoporosis, pp. 107-123 [P Burkhardt, B Dawson-Hughes and R Heaney, editors]. San Diego, CA: Academic Press.

Specker BL (1996) Evidence for an interaction between calcium intake and physical activity on changes in bone mineral density. Journal of Bone and Mineral Research 11, $1539-1544$.

Sugiyama T, Yamaguchi A \& Kawai S (2002) Effects of skeletal loading on bone mass and compensation mechanism in bone: a new insight into the 'mechanostat' theory. Journal of Bone Mineral Metabolism 20, 196-200.

Takada H, Washino K, Nagashima M \& Iwata H (1998) Response of parathyroid hormone to anaerobic exercise in adolescent female athletes. Acta Paediatrica Japonica 40, 73-77.

Turner CH \& Robling AG (2003) Designing exercise regimens to increase bone strength. Exercise and Sport Science Reviews 31, $45-50$.

Turner CH, Takano Y \& Owan I (1995) Aging changes mechanical loading thresholds for bone formation in rats. Journal of Bone and Mineral Research 10, 1544-1549.

Uusi-Rasi K, Sievanen H, Pasanen M, Oja P \& Vuoiri I (2002) Association of calcium intake and physical activity with bone density and size in premenopausal and postmenopausal women: a peripheral quantitative computed tomography study. Journal of Bone and Mineral Research 17, 544-552.

Welsh L, Rutherford OM, James I, Crowley C, Comer M \& Wolman R (1997) The acute effects of exercise on bone turnover. International Journal of Sports Medicine 18, 247-251.

Whitfield JF, Morley P \& Willick GE (1996) Stimulation of the growth of femoral trabecular bone in ovariectomised rats by the novel parathyroid fragment, hPTH (1-31) $\mathrm{NH}_{2}$ (Ostabolin). Calcified Tissue International 58, 81-87.

Wolff J (1892) The Law of Bone Transformation. Berlin: Hirshworld. 